seems to make much difference to the overall incidence of chest complications.

Prophylactic antibiotics, too, have been generally viewed with reserve. Several reports have shown no overall benefit, ${ }^{12-14}$ but another study, in which the appropriate antibiotics were given in therapeutically effective regimens, showed a reduction in the frequency of infections. ${ }^{15}$ No benefit was found from routine bronchodilator treatment.

Improving the relief of pain has proved equally disappointing as an approach to preventing chest infections. Additional morphine $^{15}$ was of no benefit, and systemic analgesia with procaine, while effective in helping patients to clear sputum, had only a marginal influence on vital capacity. ${ }^{16}$ Mid-axillary nerve blocks of the 6 th to 11 th intercostal nerves were no more effective. ${ }^{17}$ One early report suggested that epidural opiates do not restore pulmonary mechanics to anything like normal either, ${ }^{18}$ suggesting that reflex muscle spasm is as important as the pain itself. Even so, effective relief of pain has yet to be shown to be worthless in terms of actual complications rather than changes in pulmonary function.

There remains the observation in 1976 that the respiratory stimulant doxapram reduced the incidence of cough and expectoration of purulent sputum without any major effect on analgesia. ${ }^{19}$ More recently doxapram was, however, found not to have any effect in patients with preoperative symptoms having thoracotomies who were given prophylactic antibiotics, ${ }^{20}$ a finding in keeping with another study which found a beneficial effect from doxapram only in patients not given antibiotics. ${ }^{21}$

What conclusions can be reached? Prophylactic treatment of any kind seems scarcely justifiable for all patients, since some $80 \%$ will suffer no complications; but either doxapram or prophylactic antibiotics may reasonably be prescribed for patients at high risk.

Professor of Anaesthetics,

M D VICKERS

Welsh National School of Medicine,

Cardiff CF4 4XN

1 Garibaldi RA, Britt MR, Coleman ML, Reading JC, Pace NL. Risk factors for postoperative pneumonia. Am $\mathcal{F}$ Med 1981;70:677-80.

2 Davidson J. Prevention of postoperative chest complications. Lancet $1953 ; \mathrm{i}: 1225-6$.

${ }^{3}$ Gawley TH, Dundee JW, Gupta PK, Jones CJ. Role of doxapram in reducing pulmonary complications after major surgery. $\mathrm{Br} \mathrm{Med} \mathfrak{f}$ $1976 ;$ i :122-4.

4 Feeley TW, Hamilton WK, Xavier B, Moyers J, Eger EI. Sterile anesthesia breathing circuits do not prevent postoperative pulmonary infection. Anesthesiology $1981 ; 54: 369-72$.

5 Garibaldi RA, Britt MR, Webster RN, Pace NL. Failure of bacterial filters to reduce the incidence of pneumonia after inhalation anesthesia. Anesthesiology $1981 ; 54: 364-8$.

${ }^{6}$ Wightman JAK. A prospective survey of the incidence of postoperative pulmonary complications. Br f Surg 1968;55:85-91.

${ }^{7}$ Palmer KNV, Sellick BA. The prevention of postoperative pulmonary atelectasis. Lancet $1953 ; \mathrm{i}: 164-8$.

${ }^{8}$ Vriu JK, Vriu RA. Effectiveness of breathing exercises in preventing pulmonary complications following open heart surgery. Phys Ther $1977 ; 57: 1367-71$.

9 Yoshida T, Ushijima Y, Inokuchi K, Hirosa T, Shirakusa T, Katayama N. Evaluation of the risk of postoperative pulmonary complications. fpn f Surg 1977;7:131-8.

10 Clague MB, Collin J, Fleming LB. Prediction of postoperative respiratory complications by simple spirometry. Ann R Coll Surg Engl 1979;61: 59-62.

11 Van De Water JM, Watring WG, Linton LA, Murphy M, Byron RL. Prevention of postoperative pulmonary complications. Surg Gyneco Obstet $1971 ; \mathbf{1 3 5}: 229-33$.

12 Barnes J, Pace WG, Trump DS, Ellison EH. Prophylactic postoperative antibiotics. Arch Surg 1959;79:190-6.

13 Thulbourne T, Young MH. Prophylactic penicillin and postoperative chest infections. Lancet 1962 ;ii:907-9.

14 Palmer KNV, Sellick BA. Effect of procaine penicillin and breathing exercises in postoperative pulmonary complications. Lancet 1952; i: $3: 5-6$.

${ }^{15}$ Coll.ns CD, Darke CS, Knowelden J. Chest complications after upper abdominal surgery: their anticipation and prevention. $\mathrm{Br} M e d \mathcal{F} 1968$; : 401-6.
${ }^{16}$ Pooler HE. Relief of post-operative pain and its influence on vital capacity. Br Med f 1949;ii:1200-3.

17 McCleery RS, Zollinger R, Lenahan NE. A clinical study of the effect of intercostal nerve block with nupercaine in oil following upper abdominal surgery. Surg Gynecol Obstet 1948;86:680-6.

${ }^{18}$ Bromage PR, Camporesi E, Chestnut D. Epidural narcotics for postoperative analgesia. Anesth Analg (Cleve) 1980;59:473-80.

${ }^{19}$ Gawley TH, Dundee JW, Gupta PK, Jones CJ. Role of doxapram in reducing postoperative pulmonary complications after major surgery. Br Med f 1976;i:122-4.

${ }^{20}$ Sebel PS, Kershaw EJ, Rao WS. Effects of doxapram on postoperative pulmonary complications following thoracotomy. $\mathrm{Br} \mathcal{F}$ Anaesth 1980; 52:81-4.

${ }^{21}$ Downing JW, Jeal DE, Allen PJ, Buley R. Doxapram hydrochloride and pulmonary complications after lower abdominal surgery. $\mathrm{Br} \mathcal{F}$ Anaesth $1977 ; 49: 473-7$

\section{Dog bites man}

Writing about dogs is apt to stir passions, but statistics at least give a dispassionate starting point. Every year in the United States a million dogs bite the hands that feed them and doubtless shatter the illusion of trust and friendship. But is it the dog's fault? The highly strung, untrained, bored dog may turn on the taunting child; the one goes to the condemned cell and the other to the accident and emergency department. How should the wound be treated?

Animal teeth are far from clean and sharp and so create a contused and contaminated wound, in which bacteria may multiply and scar tissue may form. The prevention of wound sepsis has both surgical and medical aspects. Careful cleaning, irrigation, trimming of wound margins, elimination of dead space during closure, and avoiding overtension of sutures are all important factors. Two cardinal sins to be avoided are shaving eyebrows and failing to match the vermilion of the lips. Use of fine suture materials, removed early and replaced by surface closures, will reduce the chance of skin marking or sepsis. Only in extensive wounds or difficult cases is delayed primary suture usually required.

The medical aspect of management includes prophylaxis against tetanus and, where appropriate, rabies. The controversial issue, however, is the prevention or management of wound sepsis. The dog's mouth acts as host to a wide range of pathogens, including Pseudomonas spp, Staphylococcus aureus, Streptococcus viridans, and Pasteurella multocida. A greater risk of sepsis is to be found in patients aged over 50, wounds over 24 hours old, puncture wounds, injuries of the hand, and the presence of pre-existing illness. Among the reported complications of wound sepsis are abscess formation, osteomyelitis, ${ }^{1}$ and disseminated intravascular coagulation.

Prevention of infection is obviously the ideal. Callaham ${ }^{2}$ favours the use of prophylactic antibiotics, especially in the case of bites on the hands. The choice of antibiotic lies between the penicillinase-resistant broad-spectrum penicillins and the equivalent cephalosporins with an early parenteral first dose as the ideal. ${ }^{3}$ Callaham recommends erythromycin or tetracycline as an alternative for those significantly allergic to the penicillin group, but co-trimoxazole might be considered as a better alternative with the added advantage of being active against other Gram-negative organisms. Elenbaas $e t$ al, ${ }^{4}$ in contrast, recently completed a prospective, double-blind, placebocontrolled study on the use of prophylactic oxacillin in dog-bite wounds and concluded that prophylactic antibiotics were of no value in the care of dog-bite injuries treated within 24 hours of accident. (Oxacillin is not much used in Britain.) If nothing 
else the paucity of published studies on this topic shows that insufficient attention is given to the review of the more common conditions. The report by Elenbaas et al is interesting, but until it is confirmed by further study I shall continue the precaution of prescribing early antibiotics, at least for the more serious wounds in patients with identifiable risk factors.

If the patient develops clinical sepsis then the organism responsible must be sought carefully. In particular the laboratory should be told the history of the dog bite so that the pathologist may initiate careful aerobic and anaerobic culture and sensitivity tests. Fiala $e t a^{5}$ collected reports on 17 patients with Gram-negative bacteraemia, of whom two died in renal failure with disseminated intravascular coagulation, and themselves described a fatal coagulopathy with bacteroides sepsis. The patient who presents with spreading sepsis, fever, rigors, and constitutional upset will require a blood culture among other investigations, again detailing the cause of the wound on the request form. The laboratory will then look not only for Gram-negative rods and $P$ multocida but also for anaerobes. Until the results can be discussed with the bacteriologist metronidazole should be considered as a supplement to the initial antibiotic.

One final consideration should be the possibility of radiological investigation. I have seen a compound fracture of a metacarpal from an Alsatian bite and have found a broken tooth in a wound. Careful clinical examination is all important, as a retained foreign body may be keeping the sepsis going.

The postman's occupational hazard, the butt of the musichall joke, is therefore no laughing matter. The wound is painful, the surgery must be painstaking, the medical management is still insufficiently researched, and the complications must be carefully investigated.

Consultant in Accident and Emergency Medicine,

Royal United Hospital,

Bath BAI 3NG

1 Jarvis WR, Banko S, Snyder E, Baltimore RS. Pasteurella multocida. Osteomyelitis following dog bites. Am F Dis Child 1981;135:625-7.

${ }^{2}$ Callaham M. Dog bite wounds. FAMA 1980;244:2327-8.

3 Callaham M. Dog bite wounds. $¥ A M A$ 1981;246:834.

${ }^{4}$ Elenbaas RM, MCNabney WK, Robinson WA. Prophylactic antibiotics and dog bite wounds. $\mathcal{F} A M A 1981 ; 246: 833-4$.

${ }^{5}$ Fiala $M$, Bauer $H$, Khaleeli $M$, Giorgio A. Dog bite bacteroides infection, coagulopathy, renal microangiopathy. Ann Intern Med 1977;87:248-9.

\section{Cuts and excellence}

The progressive impoverishment of the British university system, begun a little over a year ago, is now affecting medical schools, despite their protection in the first round of cuts. The University Grants Committee has specifically stated that this time round the medical schools will have to suffer along with the rest. In practice, the cuts are hitting medical academics harder and more quickly than many people realise (see $p$ 335). The first reason for medical schools suffering more is their high turnover of staff, particularly junior staff. Over three-quarters of university expenditure is on staff salaries, and economies can now be achieved only by cutting staff. In the absence of any planned policy of reducing staff, many universities have adopted a policy of freezing all posts that become vacant. Thus medical faculties are losing more staff than other faculties. Furthermore, as the most able are the most likely to be offered new jobs and leave, this indiscriminate policy will achieve the opposite of preserving the excellent.

The second problem for the medical faculties is that theyc have more commitments than the others. Most university departments are committed only to teaching and research, but $\overline{\bar{\sigma}}$ clinical medical departments have a commitment also toग service work-to diagnosing and treating patients. Evidence is $\mathbb{\infty}$ now beginning to accumulate to show that routine services like laboratory-based services, which are mostly provided by university departments, are being overstretched, and in suchọ circumstances teaching and research-the main functions ofo medical schools-are going by the board. Furthermore, many new and highly specialist services are provided entirely by $\frac{\infty}{\sigma}$ universities, and some of these-for example, some cardiologyळ services in Southampton-are disappearing as lecturers leaveœ and are not replaced.

If medical academics respond to these events with a mixture of apathy and despair Britain's medical faculties will simply $\vec{\rho}$ become part of the universities' slide into grey mediocrity. Some voices are calling for a more radical response. Universi -3 . ties should, says Nature, ${ }^{1}$ be free to compete with each other, $\infty$ to pay their staff what they can afford, and so create a system in which some would become recognised as centres of academic $\frac{\omega}{N}$ excellence while others were content to concentrate on teaching: students. Tenure should be limited-and the erosion of the common academic sense of security would be no bad thing. ㅇ

Certainly there is a case for medical faculties looking at a $\omega$ series of options as alternatives to passive acceptance of the results of their current financial starvation.

The Flowers proposals ${ }^{23}$ for the amalgamations and fusions of the medical schools in London were talked to death but they could have paved the way for a smaller, leaner, more efficient ${ }^{\circ}$ grouping of medical teaching in the metropolis. Medical ${ }^{N}$ student numbers might be re-examined-if only the financialo benefits of cuts could be guaranteed to be used to maintain s standards. And if Nature is right-and experience in other countries suggests that undergraduate teaching can be $\frac{0}{\mathrm{O}}$ separated from research without any loss in quality - then the $\stackrel{\varrho}{\rightarrow}$ process of rationalisation might be extended to many pedestrian research departments.

One of the most distressing features of the current crisis is that medical schools do not have a single forum in which to discuss these options or a single voice with which to confront the UGC and the Government. Nevertheless, one body that should surely speak for all medical schools is the $\underline{3}$. General Medical Council. Is it investigating the effect of $\delta$ academic cuts on medical education and does it have anything ₹ to say ? A second body that might help with long-term planning 9 is Renée Short's House of Commons Social Services Com- $N$ mittee, which is considering producing a report on the effect of academic cuts on the health services. We would urge it to을. consider, too, the effects on undergraduate and postgraduate $N$ medical education and on medical research. The royal colleges, ్ㅔ the BMA, and the Committee of Vice Chancellors and Principals should all have contributions to make. Sadly, as the history of the Flowers report and its many predecessors shows, $\stackrel{\mathbb{D}}{\mathscr{D}}$ the multiplicity of these talking shops seems to guarantee a lack? of any consensus-while no single body has both the will and 0 the power to act. Without action, the future is bleak indeed. $\frac{\vec{D}}{\mathrm{D}}$ So who will have the courage to bell the cat?

\footnotetext{
1 Anonymous. British academic agony. Nature $1981 ; 294: 682$.

University of London. London medical education-a new framework. Report of a Working Party on Medical and Dental Teaching Resources, chairman Lord Flowers. London: University of London, 1980.

3 Anonymous. London's Medicine. Br Med f 1980;280:665-6.
} 